\title{
Protozoa population and carbohydrate fermentation in sheep fed diet with different plant additives
}

\author{
Małgorzata P. Majewska ${ }^{1} \star$, Renata Miltko ${ }^{1}$, Grzegorz Bełżecki ${ }^{1}$, \\ Aneta Kędzierska ${ }^{1}$, and Barbara Kowalik ${ }^{1}$
}

\author{
* Corresponding Author: \\ Małgorzata P. Majewska \\ Tel: +48-22-7653365, Fax: +48-22-7653302 \\ E-mail:m.majewska@ifzz.pl \\ ${ }^{1}$ Department of Animal Nutrition, \\ The Kielanowski Institute of Animal \\ Physiology and Nutrition, Polish Academy of \\ Sciences, Jabłonna 05-110, Poland \\ ORCID \\ Małgorzata P. Majewska \\ https://orcid.org/0000-0002-6078-9678 \\ Renata Miltko \\ https://orcid.org/0000-0001-6835-4807 \\ Grzegorz Bełżecki \\ https://orcid.org/0000-0003-2237-1454 \\ Aneta Kędzierska \\ https://orcid.org/0000-0001-6337-8797 \\ Barbara Kowalik \\ https://orcid.org/0000-0003-3884-1967
}

Submitted Jul 10, 2020; Revised Aug 21, 2020; Accepted Oct 5, 2020
Objective: The aim of the study was to compare the effect of two plant additives, rich in polyphenolic compounds, supplemented to sheep diets on microorganisms and carbohydrate fermentation in rumen.

Methods: In the experiment, 6 ewes of the Polish Mountain breed were fitted with ruminal cannulas. Sheep were divided into three feeding groups. The study was performed in a crossover design of two animals in each group, with three experimental periods $(n=6$ per each group). The animals were fed a control diet (CON) or additionally received $3 \mathrm{~g}$ of dry and milled lingonberry leaves (VVI) or oak bark (QUE). Additionally, plant material was analyzed for tannins concentration.

Results: Regardless of sampling time, QUE diet increased the number of total protozoa, as well as Entodinium spp., Diplodinium spp. and Isotrichidae family, while decreased bacterial mass. In turn, a reduced number of Diplodinium spp. and increased Ophryoscolex spp. population were noted in VVI fed sheep. During whole sampling time $(0,2,4$, and $8 \mathrm{~h})$, the number of protozoa in ruminal fluid of QUE sheep was gradually reduced as opposed to animals receiving CON and VVI diet, where rapid shifts in the protozoa number were observed. Moreover, supplementing sheep with QUE diet increased molar proportions of butyrate and isoacids in ruminal fluid. Unfortunately, none of the tested additives affected gas production.

Conclusion: The addition of VVI or QUE in a small dose to sheep diets differently affected rumen microorganisms and fermentation parameters, probably because of various contribution of catechins in tested plant materials. However, it is stated that QUE diet seems to create more favorable conditions for growth and development of ciliates. Nonetheless, the results of the present study showed that VVI and QUE additives could serve as potential natural modulators of microorganism populations and, consequently, carbohydrate digestion in ruminants.

Keywords: Lingonberry Leaves; Oak Bark; Microorganisms; Short-chain Fatty Acids; Methane; Sheep

\section{INTRODUCTION}

Unlike monogastric animals, the presence of the rumen, which acts as a fermentation chamber, enables ruminants to utilize roughage as a source of energy. Additionally, ruminants do not produce enzymes responsible for degrading fibrous plant material. Thus, digestion in the rumen occurs only due to the symbiotic relationship of bacteria, protozoa, and fungi with the host organism [1]. Interestingly, the composition of rumen microorganisms may be affected by several factors, including diet composition, age, health of the host animal, as well as geographical location and feed regimen [2].

Recently, scientists have been seeking natural agents in ruminants' nutrition, which may 
directly or indirectly modify the ruminal microorganism population as well as carbohydrate fermentation and methanogenesis. The example of such factors can be herbal additives, including lingonberry leaves and oak bark, with properties applicable in medicine. Lingonberry (Vaccinium vitis-idaea L.) is an eminent fruit crop with health promoting properties. Interestingly, leaves and berries of lingonberry contain a lot of polyphenolic compounds, which exert high antioxidant activities [3]. Oak (Quercus sp.) is a popular wood in the cooperage industry and in the barrels and stoppers production. Until recently, oak bark was treated as a waste of wood transformation with scarce application and relatively low price [4]. But similar to aforesaid lingonberry, it is a valuable source of polyphenols. It became popular in traditional medicine for treating different illnesses and wounds because of its antioxidant, antibacterial and anti-inflammatory activities [3].

The common feature of both plants is the presence of secondary metabolites, for instance, tannins. Generally, tannins are characterized as water-soluble polyphenols of various molecular mass, commonly found in nature [5]. Due to their different molecular weights, they may exhibit different reactivity and biological activity. On this basis, such compounds are divided into two main groups: hydrolysable and condensed tannins [5]. Kylli et al [6] reported that the main phenolic compounds found in lingonberries are proanthocyjanidins (condensed tannins), which consist of catechin, epicatechin, gallocatechin and epigallocatechin units. By contrast, in oak bark, hydrolysable tannins (including galloand ellagitannins) constitute the overwhelming number of polyphenolic compounds, while complex tannins as well as proanthocyjanidins (oligomers and polymers) are in the minority [4].

Several studies have documented that the usage of plants containing tannins in ruminants' diet may affect microorganisms number, digestive enzymes, the degradability of diet components and, consequently, nutrient availability in other parts of the digestive tract [7-9]. Nonetheless, it is worth noting that tannins are generally classified as anti-nutritional compounds, which may considerably limit their use in animal nutrition. For that reason, their contribution in the diets should be monitored with the greatest caution.

Interestingly, a considerable part of the researches on bioactive compounds of natural additives were in vitro studies, while studies performed on ruminants are often limited.
Unfortunately, information about the effect of lingonberry leaves and oak bark addition, on rumen microorganisms and fermentation parameters in ruminants are still scarce.

It was hypothesized that supplementing sheep diets with lingonberry leaves and oak bark, may affect microorganism populations as well as end products of ruminal carbohydrate fermentation.

Hence, the aim of the present study was to determine the effect of two natural additives, differing in polyphenolic compounds contents (tannins), to sheep diets on rumen microorganisms and carbohydrate fermentation parameters. To identify the whole appearing changes in time due, protozoa number, $\mathrm{pH}$ of rumen fluid, the molar proportion of short chain fatty acid (SCFA) as well as estimated gas production were measured before feeding and at 2, 4, and 8 hours after feeding, whereas samples for bacterial biomass estimation were pooled.

\section{MATERIALS AND METHODS}

All procedures performed in the present study were accepted by the Local Animal Care and Ethics Committee for Animal Experiment in Warsaw (Poland); permission no. 51/2009.

\section{Animals and diets}

The experiment was carried out on 6 ewes of the Polish Mountain breed with an average body weight of $33 \pm 1.1 \mathrm{~kg}$, fitted with rumen cannulas. The rumen fistula was placed in the dorsal part of the rumen sac on the left side of the body. Sheep were housed in the individual pens, padded with straw, with ad libitum access to water and salt licks.

The experiment was performed in a cross-over design of two animals in each group with three periods $(n=6$ per group; Table 1). Each period of the experiment lasted 37 days, including 14 days of gradual transition to the diet, 21 days of adaptation to the specific diet and 2 days of sampling. The control diet $(\mathrm{CON})$ consisted of meadow hay, barley meal, soybean meal and vitamin-mineral premix (Table 2). Sheep in experimental groups additionally received $3 \mathrm{~g}$ of dry and milled lingonberry leaves (Vaccinium vitis-idaea L., VVI) or oak bark (Quercus sp., QUE), which were thoroughly mixed with the control diet before administration. The animals were fed twice a day at $7.00 \mathrm{am}$ and $15.00 \mathrm{pm}$. Plant material was analyzed for tannins concentrations.

Table 1. Experiment design

\begin{tabular}{lllllll}
\hline Period/sheep & $\mathbf{1}$ & $\mathbf{2}$ & $\mathbf{3}$ & $\mathbf{4}$ & $\mathbf{5}$ & $\mathbf{6}$ \\
\hline I (37 days) & CON & CON & VVI & VVI & QUE & QUE \\
II (37 days) & QUE & QUE & CON & CON & VVI & VVI \\
III (37 days) & VVI & VVI & QUE & QUE & CON & CON \\
\hline
\end{tabular}

CON, control diet; VVI, diet with lingonberry leaves addition; QUE, diet with oak bark addition. 
Table 2. Composition of control diet for sheep ${ }^{1)}$

\begin{tabular}{lc}
\hline Item & Control diet \\
\hline Components (\% of dry matter, DM) & \\
Meadow hay & 59.7 \\
Barley meal & 28.4 \\
Soybean meal & 9.84 \\
Vitamin-mineral premix ${ }^{2)}$ & 2.07 \\
Chemical composition (\% of DM) & \\
Organic matter & 94.0 \\
Crude protein ${ }^{3)}$ & 15.2 \\
Crude fat & 2.00 \\
Starch & 24.7 \\
NDF & 51.1 \\
ADF & 26.0 \\
ADL & 3.98 \\
Crude ash & 5.85 \\
Nutritive value) & \\
PDI (g) & 95.3 \\
UFV (per kg) & 0.80 \\
SFU (per kg) & 0.60 \\
\hline
\end{tabular}

DM, dry matter; NDF, neutral detergent fibre; ADF, acid detergent fibre; $A D L$, acid detergent lignin; PDI, protein digested in small intestine; UFV, feed unit for maintenance and meat production; SFU, fill unit for sheep.

${ }^{1)}$ Diet formulated according to the ruminant nutrition recommendations [11].

2) Polfamix O-K (Trouw Nutrition Polska, Grodzisk Mazowiecki, Poland) in kg: Ca 240 g, Na 60 g, P 120 g, Mg 65 g, Zn 2.5 g, Mn 3.0 g, vit. E 1.5 g, Se 0.003 g, Co 0.015 g; vit. A 300,000 IU, vit. $D_{3} 30,000$ IU.

3) Expressed as $\mathrm{N} \times 6.25$

${ }^{4)}$ Calculated for all diet components according to the values read from the tables containing information about chemical composition and nutritional value of feed [11].

The amount of tannins in the preparations was 10.3 and 4.0 $\mathrm{g}$ of catechins equivalent per $\mathrm{kg}$ of dry matter (DM) of the additive, for VVI and QUE respectively [10]. The contribution of components in the DM of feed and their chemical composition is presented in Table 2. The energy value of the food was calculated based on feeding standards for ruminants IZ PIB-INRA [11]. The DM uptake of control diet was 919 g per day.

\section{Rumen fluid sampling}

The collection of rumen fluid was performed for two consecutive days. Rumen fluid samples (about $270 \mathrm{~mL}$ ) were taken before feeding and at 2, 4, and 8 hours after feeding. The rumen fluid was filtrated through a complex of 4 layers of surgical gauze and its $\mathrm{pH}$, protozoan count and SCFA concentration were determined.

\section{Analytical methods}

The chemical composition of feed, including DM (934.01), crude protein (954.01), crude fiber (978.10), acid detergent fibre and acid detergent lignin (973.18), neutral detergent fibre (2002.04), starch (920.4) and crude ash (930.05) contents, was determined according to the AOAC method [12].

Protozoa number and bacterial mass: For the determination of protozoan number, $5 \mathrm{~mL}$ of rumen fluid were fixed with $10 \mathrm{~mL}$ of $4 \%$ formaldehyde solution. Such samples were stored in tightly closed containers at $4^{\circ} \mathrm{C}$ until analysis. The number of protozoa was identified and classified according to Dogiel [13] and determined using a light microscope according to the method of Miltko et al [14].

Rumen bacterial biomass was determined according to the method of Michałowski et al [15]. For this measurement unfiltered rumen fluid samples were used, so as not to remove bacteria attached to the feed particles accidentally. Briefly, the rumen fluid was centrifuged in the three-step centrifugations. The first centrifugation lasted 10 minutes at $600 \times \mathrm{g}$, which allowed removal of protozoa and feed residues (if present). The collected supernatant was subjected to centrifugation for another 30 minutes at 30,000 $\times$ g. The sediment was dissolved in $0.9 \%$ saline solution and centrifuged once again at the same parameters as previous centrifugation to obtain purified bacteria material. After last centrifugation, bacterial pellet was dissolved in $5 \mathrm{~mL}$ of $0.9 \%$ saline solution to accurately transfer it from the tube and weighed. Threestep centrifugations for all sampling times (before feeding and at 2, 4, $8 \mathrm{~h}$ after feeding) were performed. Due to the small amounts of bacterial mass obtained from the ruminal fluid, the samples from different time points were pooled and expressed as $\mathrm{g} / 8 \mathrm{~h}$, taking into account the known volumes of rumen fluid and salt solution used during centrifugation, as follows:

$$
\begin{aligned}
& \text { Bacterial mass }(\mathrm{g} / 8 \mathrm{~h}) \\
& =\frac{\text { sum of bacterial mass }(0,2,4,8 \mathrm{~h})-20 \mathrm{~mL} \text { of saline solution }}{\text { sum of rumen fluid }(0,2,4,8 \mathrm{~h})} \times 100
\end{aligned}
$$

According to the above equation, the sum of bacterial mass, volumes of rumen fluid and saline solution at different time points were used. Finally, the bacterial pellets of each animal from CON, VVI, and QUE groups were dissolved in $0.9 \%$ saline solution and stored at $-24^{\circ} \mathrm{C}$.

$\mathrm{pH}$ and short-chain fatty acids: The acidity of rumen fluid was immediately determined with a F72 Beckman pH-meter during sampling time.

For the determination of SCFA, $5 \mathrm{~mL}$ of rumen fluid were treated with $0.5 \mathrm{~mL}$ of $85 \%$ of formic acid, then centrifuged at $11,000 \times \mathrm{g}$ for $25 \mathrm{~min}$ and finally stored in sealed vials at $4^{\circ} \mathrm{C}$ until analysis. One $\mathrm{ml}$ of 4-methylvaleric acid in $100 \mathrm{~mL}$ of water solution was added to each sample and served as an internal standard during analysis. The concentrations of SCFA in the rumen fluid samples were determined using a gas chromatograph (Shimadzu GC-2010, Tokyo, Japan) equipped with a $30 \mathrm{~m}$ capillary column $(0.25 \mathrm{~mm}$ i.d. $\times 0.25$ $\mu \mathrm{m}$ film thickness) and a flame ionisation detector, with 
helium as a carrier gas, according to the method of Miltko et al [16].

Gas production: Based on the concentrations of specific SCFA, the quantification of methane and carbon dioxide content in the rumen fluid of sheep according to the molar proportions of SCFA was provided (a theoretical fermentation balance) [17]:

\section{$57.5\left(\mathrm{C}_{6} \mathrm{H}_{12} \mathrm{O}_{6}\right) \rightarrow 65$ acetate $\left(\mathrm{C}_{2}\right)+20$ propionate $\left(\mathrm{C}_{3}\right)$ +15 butyrate $\left(\mathrm{C}_{4}\right)+60 \mathrm{CO}_{2}+35 \mathrm{CH}_{4}+25 \mathrm{H}_{2} \mathrm{O}$.}

According to above reaction (i.e. the ruminal microbial fermentation), for a molar distribution of 65 acetate: 20 propionate: 15 butyrate $\left(65 \mathrm{C}_{2}: 20 \mathrm{C}_{3}: 15 \mathrm{C}_{4}\right), 60$ moles of $\mathrm{CO}_{2}$ and 35 moles of $\mathrm{CH}_{4}$ are formed. Thus, based on this equation, the following amounts of the individual acids are generated from 1 mole of glucose:

$$
\begin{aligned}
& 1.13 \mathrm{C}_{2}+0.3478 \mathrm{C}_{3}+0.2608 \mathrm{C}_{4} \\
& +1.043479 \mathrm{CO}_{2}+0.608696 \mathrm{CH}_{4} .
\end{aligned}
$$

Therefore, the theoretical molar proportions as well as theoretical concentrations of microbiota fermentation products are as follows:

$$
\begin{aligned}
& 1 \mathrm{M} \mathrm{C}_{2}+0.307787 \mathrm{M} \mathrm{C}_{3}+0.2308 \mathrm{M} \mathrm{C}_{4} \\
& +0.9234327 \mathrm{M} \mathrm{CO}_{2}+0.5386690265 \mathrm{M} \mathrm{CH}_{4} .
\end{aligned}
$$

Based on the experimental concentrations of $\mathrm{C}_{2}, \mathrm{C}_{3}$, and $\mathrm{C}_{4}$ obtained in the present study $(\mathrm{mM} / 100 \mathrm{~mL})$, the critical concentrations of $\mathrm{C}_{2}, \mathrm{C}_{3}$, or $\mathrm{C}_{4}$ should be found. In fact, in the analyzed ovine ruminal fluid, the concentrations of two SCFA (i.e. $\mathrm{C}_{2}, \mathrm{C}_{3}$, or $\mathrm{C}_{4}$ ) were generally higher than the theoretical concentrations of $\mathrm{C}_{2}, \mathrm{C}_{3}$, or $\mathrm{C}_{4}$ [17]. Importantly, the critical concentrations of these acids determined the amounts of $\mathrm{CH}_{4}$ and $\mathrm{CO}_{2}$ generated $(\mathrm{mM} / 100 \mathrm{~mL})$, according to the fermentation reaction. The critical concentrations of aforesaid acids have been designated based on the obtained experimental data by dividing the concentrations of these acids with each other in the Microsoft Excel program.

\section{Statistical analysis}

The results of the current study were presented as means and pooled standard error of mean (SEM). To assess the normality of the distribution of the obtained data, the Shapiro-Wilk test was used. Additionally, the homogeneity of variances was also checked by Levene's test. Data with abnormal distribution were transformed into natural logarithms. The results were subjected to two-way analysis of variance (ANOVA) (with two factors: diet and sampling time; including protozoa number, $\mathrm{pH}$, SCFA concentration and gas production), or one-way ANOVA (one factor: diet; including bacterial bio- mass). The significance of both: i) interactions between diet and sampling time (two-way ANOVA) and/or ii) differences between dietary treatments (one-way ANOVA) was determined by a Tukey test. The differences were considered significant at $\mathrm{p} \leq 0.05$. However, differences at $\mathrm{p}>0.05$ were defined as trends. The statistical analysis was performed using the Statistica program (StatSoft, Polska, 2011).

\section{RESULTS}

\section{Rumen microorganisms}

A significant interaction between diet and sampling time were noted for total protozoa number and their species ( $\mathrm{p} \leq 0.001$; Table 3). However, the effect of plant additives on protozoa population was distinct.

Supplementing sheep with QUE addition significantly increased total number of protozoa and Entodinium spp. at 2 and 4 hours after feeding, and, simultaneously reduced their number at 8 hours after feeding, compared to the $\mathrm{CON}$ and VVI groups $(\mathrm{p} \leq 0.001)$. Furthermore, feeding sheep with QUE diet also significantly increased the Diplodinium spp. population before feeding (vs VVI group) as well as at 2 (vs CON group) and 4 hours after feeding (vs VVI diet) and reduced their number at 8 hours after feeding, compared to the CON and VVI groups. A greater number of protozoa of the Dasytricha genus was found in QUE sheep at 2 and 4 hours after feeding in comparison to the CON and VVI groups, while reduction of their population was showed at 8 hours after feeding, compared to the CON group $(\mathrm{p} \leq 0.001)$.

The addition of VVI to sheep diets significantly reduced the number of Diplodinium spp. population before and at 4 hours after feeding in comparison to the CON and QUE groups, while increased their number at 8 hours after feeding in comparison to QUE sheep ( $\mathrm{p} \leq 0.001)$. Furthermore, there were significantly increased numbers of Ophryoscolex spp. protozoa in VVI sheep before feeding and at 2 hours after feeding, compared to the CON group, as well as at 8 hours in comparison to the QUE group.

Both plant additives significantly increased the Isotricha spp. number before feeding, compared to the CON sheep $(p \leq 0.001)$, while then some changes in time due were noted. Supplementing sheep with QUE diet increased Isotricha spp. population at 2 hours and reduced their number at 8 hours after feeding in comparison to the CON and VVI groups.

Worth noting was fact that all changes in protozoa number after feeding time in QUE sheep were not as spectacular as observed regarding to the $\mathrm{CON}$ and VVI groups. It means that during whole sampling time $(0,2,4$, and $8 \mathrm{~h})$, the number of protozoa in ruminal fluid of sheep receiving QUE diet was gradually reduced $(\mathrm{p} \leq 0.001)$. On the contrary, drastic reduction of protozoa number was reported at 2 and $4 \mathrm{~h}$ after feeding in CON and VVI animals and then slightly increased 
Table 3. Concentration of ciliates $\left(\times 10^{4} / \mathrm{mL}\right)$ and bacterial mass $(\mathrm{g} / 8 \mathrm{~h})$ in sheep rumen fluid

\begin{tabular}{|c|c|c|c|c|c|c|c|c|c|}
\hline \multirow{2}{*}{ Item } & \multirow{2}{*}{ Diet $^{1)}$} & \multicolumn{4}{|c|}{ Time (h) } & \multirow{2}{*}{ SEM } & \multirow{2}{*}{$D^{2)}$} & \multirow{2}{*}{$\mathrm{T}^{2)}$} & \multirow{2}{*}{$D \times T^{2)}$} \\
\hline & & 0 & 2 & 4 & 8 & & & & \\
\hline \multirow[t]{3}{*}{ Total ciliate } & CON & $94.7^{a}$ & $36.4^{\mathrm{bx}}$ & $51.2^{c x}$ & $77.5^{\mathrm{dx}}$ & 2.83 & $<0.001$ & $<0.001$ & $<0.001$ \\
\hline & VVI & $84.1^{\mathrm{a}}$ & $38.5^{\mathrm{bx}}$ & $46.4^{\mathrm{bx}}$ & $75.3^{c x}$ & & & & \\
\hline & QUE & $93.5^{\mathrm{a}}$ & $89.4^{\text {ay }}$ & $74.0^{\text {ay }}$ & $49.7^{\text {by }}$ & & & & \\
\hline \multirow[t]{3}{*}{ Entodinium } & CON & $82.8^{a}$ & $31.3^{\mathrm{bx}}$ & $44.6^{c x}$ & $63.3^{d x}$ & 2.47 & $<0.001$ & $<0.001$ & $<0.001$ \\
\hline & $\mathrm{VVI}$ & $71.8^{\mathrm{a}}$ & $32.3^{b x}$ & $40.9^{b x}$ & $63.6^{c x}$ & & & & \\
\hline & QUE & $80.2^{a}$ & $77.2^{\text {ay }}$ & $64.1^{\text {ay }}$ & $41.4^{\text {by }}$ & & & & \\
\hline \multirow[t]{3}{*}{ Diplodinium } & CON & $4.95^{\mathrm{ax}}$ & $1.70^{\mathrm{bx}}$ & $3.20^{c x}$ & $4.47^{\mathrm{ax}}$ & 0.160 & $<0.001$ & $<0.001$ & $<0.001$ \\
\hline & VVI & $2.83^{a y}$ & $2.22^{\mathrm{axy}}$ & $1.78^{\text {by }}$ & $4.34^{c x}$ & & & & \\
\hline & QUE & $5.18^{a x}$ & $3.00^{\text {by }}$ & $2.60^{b x}$ & $2.55^{\text {by }}$ & & & & \\
\hline \multirow[t]{3}{*}{ Ophryoscolex } & CON & $0.63^{\mathrm{acx}}$ & $0.14^{b x}$ & $0.44^{c}$ & $1.12^{\mathrm{ax}}$ & 0.062 & $<0.001$ & $<0.001$ & 0.003 \\
\hline & VVI & $1.42^{\text {ay }}$ & $0.36^{\text {by }}$ & $0.65^{c}$ & $1.02^{d x}$ & & & & \\
\hline & QUE & $1.34^{a x y}$ & $0.26^{\mathrm{bxy}}$ & $0.70^{\mathrm{a}}$ & $0.63^{\text {ay }}$ & & & & \\
\hline \multirow[t]{3}{*}{ Isotricha } & CON & $1.08^{a x}$ & $0.44^{\mathrm{bx}}$ & $0.84^{\mathrm{a}}$ & $1.90^{c x}$ & 0.069 & 0.510 & $<0.001$ & $<0.001$ \\
\hline & VVI & $1.47^{a y}$ & $0.58^{b x}$ & $0.61^{b}$ & $1.85^{\mathrm{ax}}$ & & & & \\
\hline & QUE & $1.50^{\text {ay }}$ & $1.38^{\text {ay }}$ & $0.85^{\mathrm{ab}}$ & $0.70^{\text {by }}$ & & & & \\
\hline \multirow[t]{3}{*}{ Dasytricha } & CON & $5.23^{a}$ & $2.82^{b x}$ & $2.18^{\mathrm{bx}}$ & $6.71^{a x}$ & 0.240 & $<0.001$ & $<0.001$ & $<0.001$ \\
\hline & VVI & $6.53^{\mathrm{a}}$ & $3.08^{b x}$ & $2.42^{b x}$ & $4.41^{c y}$ & & & & \\
\hline & QUE & $5.24^{\mathrm{a}}$ & $7.54^{\text {by }}$ & $5.80^{\text {aby }}$ & $4.40^{\text {ay }}$ & & & & \\
\hline \multirow[t]{3}{*}{ Bacterial mass } & CON & \multicolumn{4}{|c|}{$1.27^{x y}$} & 0.062 & 0.003 & - & - \\
\hline & VVI & \multicolumn{4}{|c|}{$1.51^{x}$} & & & & \\
\hline & QUE & \multicolumn{4}{|c|}{$1.07^{y}$} & & & & \\
\hline
\end{tabular}

SEM, standard error of the mean.

1) CON, control diet; VVI, diet with lingonberry leaves addition; QUE, diet with oak bark addition.

${ }^{2)} \mathrm{D}$, main effect of dietary treatment; $T$, main effect of time; $D \times T$, dietary treatment and time interaction effect.

Different superscripts in a row ( $\left.{ }^{a-d} p \leq 0.05\right)$ differ between sampling time $(0,2,4,8 \mathrm{~h})$.

Different superscripts in a column ( $\left.{ }^{x, y} p \leq 0.05\right)$ differ between diet (CON, VVI, QUE).

at $8 \mathrm{~h}$ after feeding $(\mathrm{p} \leq 0.001)$.

Feeding sheep with QUE diet significantly reduced bacterial mass in rumen fluid in comparison to VVI diet $(\mathrm{p}=0.003$; Table 3).

Indicators of rumen fermentation and gas production Any significant interaction between diet and sampling time of ruminal fluid $\mathrm{pH}$ in present study was observed ( $\mathrm{p}=0.194$; Table 4).

Likewise, the addition of both natural additives to sheep diets did not significantly affect the concentration of total SCFA ( $\mathrm{p}=0.895)$, as well as molar proportions of acetate ( $\mathrm{p}$ $=0.337)$, propionate $(\mathrm{p}=0.234)$ and valerate $(\mathrm{p}=0.182)$ in rumen fluid before and after feeding the animals.

However, significant interaction between diet and time for molar proportion of butyrate was noted $(p=0.011)$. Briefly, higher values of butyrate were documented for QUE sheep before feeding (vs VVI group), at 2 and $4 \mathrm{~h}$ after feeding (vs CON and VVI sheep) as well as at $8 \mathrm{~h}$ when compared to VVI group ( $\mathrm{p} \leq 0.001)$.

Similar dependencies were shown for molar proportions of isoacids, including isobutyric and isovaleric acids ( $\mathrm{p} \leq$ 0.001 ). Higher values of such acids were noted in sheep receiving QUE diet at 2 and $4 \mathrm{~h}$ after feeding in comparison to
CON and VVI groups ( $\mathrm{p} \leq 0.001)$.

Interestingly, some different changes in molar proportions of butyrate and isoacids in time due were observed. Generally, when adding both plant sources to sheep diets, the molar proportion of butyrate after feeding $(\mathrm{p}=0.066)$ was rather constant. On the contrary, the amount of isoacids in rumen fluid decreased after feeding time, regardless of dietary treatments $(\mathrm{p} \leq 0.001)$.

The addition of VVI and QUE to sheep diet did not significantly affect methane and carbon dioxide concentrations in rumen fluid ( $\mathrm{p}=0.158$; Table 5$)$.

\section{DISCUSSION}

The information about quantity, form (part of the plants, pure extract) as well as the presence of phenolic compounds is of utmost importance, when interpreting the results of studies using phyto-sources in animal nutrition. It is often because biologically active substances found in plant materials may differ in their properties and reactivity.

\section{Rumen microorganisms}

In ruminants, microorganisms habituating rumen play an important role and are involved in nutrient digestion [1]. 
Table 4. $\mathrm{pH}$, total short-chain fatty acids concentration $(\mathrm{mM} / 100 \mathrm{~mL})$ and molar proportions of short-chain fatty acids (\%) in rumen fluid of sheep

\begin{tabular}{|c|c|c|c|c|c|c|c|c|c|}
\hline \multirow{2}{*}{ Item } & \multirow{2}{*}{ Diet $^{1)}$} & \multicolumn{4}{|c|}{ Time (h) } & \multirow{2}{*}{ SEM } & \multirow{2}{*}{$\mathrm{D}^{2)}$} & \multirow{2}{*}{$\mathrm{T}^{2)}$} & \multirow{2}{*}{$\mathrm{D} \times \mathrm{T}^{2}$} \\
\hline & & 0 & 2 & 4 & 8 & & & & \\
\hline \multirow[t]{3}{*}{$\mathrm{pH}$} & CON & 6.73 & 6.07 & 6.11 & 6.34 & 0.026 & $<0.001$ & $<0.001$ & 0.194 \\
\hline & VVI & 6.70 & 6.15 & 6.05 & 6.33 & & & & \\
\hline & QUE & 6.41 & 5.98 & 6.01 & 6.24 & & & & \\
\hline \multirow[t]{3}{*}{ Total SCFA } & CON & 9.06 & 11.9 & 11.6 & 9.61 & 0.161 & 0.002 & $<0.001$ & 0.895 \\
\hline & VVI & 9.01 & 11.7 & 11.0 & 9.89 & & & & \\
\hline & QUE & 10.1 & 12.9 & 12.1 & 10.2 & & & & \\
\hline \multirow[t]{3}{*}{ Acetate } & $\mathrm{CON}$ & 63.9 & 64.7 & 65.7 & 65.4 & 0.304 & 0.143 & 0.024 & 0.337 \\
\hline & $\mathrm{VVI}$ & 67.7 & 64.4 & 65.1 & 67.5 & & & & \\
\hline & QUE & 65.2 & 63.1 & 64.1 & 67.1 & & & & \\
\hline \multirow[t]{3}{*}{ Propionate } & $\mathrm{CON}$ & 15.5 & 21.0 & 19.6 & 17.8 & 0.271 & $<0.001$ & $<0.001$ & 0.234 \\
\hline & VVI & 15.4 & 21.1 & 19.3 & 17.1 & & & & \\
\hline & QUE & 14.8 & 17.1 & 16.5 & 15.2 & & & & \\
\hline \multirow[t]{3}{*}{ Butyrate } & CON & $15.2^{\text {ay }}$ & $11.3^{b x}$ & $11.9^{b x}$ & $13.8^{a b x y}$ & 0.233 & $<0.001$ & 0.066 & 0.011 \\
\hline & VVI & $12.3^{x}$ & $11.4^{x}$ & $12.4^{x}$ & $12.3^{x}$ & & & & \\
\hline & QUE & $15.1^{y}$ & $15.5^{y}$ & $15.4^{y}$ & $14.3^{y}$ & & & & \\
\hline \multirow[t]{3}{*}{ Valerate } & $\mathrm{CON}$ & 1.31 & 1.43 & 1.45 & 1.16 & 0.031 & $<0.001$ & $<0.001$ & 0.182 \\
\hline & VVI & 1.14 & 1.39 & 1.56 & 1.11 & & & & \\
\hline & QUE & 1.33 & 1.82 & 1.79 & 1.22 & & & & \\
\hline \multirow[t]{3}{*}{ Isoacids ${ }^{3)}$} & CON & $4.00^{a}$ & $1.52^{b x}$ & $1.45^{b x}$ & $1.95^{\mathrm{c}}$ & 0.089 & $<0.001$ & $<0.001$ & $<0.001$ \\
\hline & VVI & $3.50^{a}$ & $1.67 b x$ & $1.66^{b x}$ & $1.97^{b}$ & & & & \\
\hline & QUE & $3.62^{\mathrm{a}}$ & $2.47^{\text {by }}$ & $2.21^{\text {by }}$ & $2.18^{b}$ & & & & \\
\hline
\end{tabular}

SEM, standard error of the mean; SCFA, short-chain fatty acids.

1) CON, control diet; VVI, diet with lingonberry addition; QUE, diet with oak bark addition.

${ }^{2)} \mathrm{D}$, main effect of dietary treatment; $T$, main effect of time; $D \times T$, dietary treatment and time interaction effect.

3) Sum of the isobutyric and isovaleric acids.

Different superscripts in a row $(a, b \leq 0.05)$ differ between sampling time $(0,2,4,8 \mathrm{~h})$;

Different superscripts in a column ( $\left.{ }^{x, y} p \leq 0.05\right)$ differ between diet (CON, VVI, QUE)

Bioactive compounds present in a fodder may directly affect the growth and activity of both rumen microflora and microfauna, as well as nutrient availability, which determine their population [8]. All changes in the microorganism populations influence digestion processes in rumen and finally the amount and type of nutrients reaching further parts of the digestive tract of ruminants. According to the systematics of Dogiel [13], the protozoa found in the rumen belong to the two main families: Ophryoscolecidae and Isotrichidae.
The first family is represented by three genera of protozoa, including Entodinium spp., Diplodinium spp. and Ophryoscolex spp., and the second by two genera, namely Isotricha spp. and Dasytricha ssp. In the present study, both VVI and QUE diets significantly affected protozoa count in the sheep rumen fluid. The largest group of protozoa were Entodinium genus in all dietary treatments. Additionally, rapid shifts in protozoa number was recorded for CON and VVI diets. On the contrary, the supplementation of QUE additive to sheep

Table 5. Gas production in sheep rumen $(\mathrm{mM} / 100 \mathrm{~mL})$

\begin{tabular}{|c|c|c|c|c|c|c|c|c|c|}
\hline \multirow{2}{*}{ Item } & \multirow{2}{*}{ Diet $^{1)}$} & \multicolumn{4}{|c|}{ Time (h) } & \multirow{2}{*}{ SEM } & \multirow{2}{*}{$D^{2)}$} & \multirow{2}{*}{$\mathbf{T}^{2)}$} & \multirow{2}{*}{$\mathrm{D} \times \mathrm{T}^{2}$} \\
\hline & & 0 & 2 & 4 & 8 & & & & \\
\hline \multirow[t]{3}{*}{ Methane $^{3)}$} & CON & 2.45 & 3.11 & 3.13 & 2.87 & 0.056 & 0.003 & $<0.001$ & 0.158 \\
\hline & VVI & 2.36 & 2.78 & 2.99 & 2.71 & & & & \\
\hline & QUE & 2.61 & 3.82 & 3.36 & 2.71 & & & & \\
\hline \multirow[t]{3}{*}{ Carbon dioxide $^{3)}$} & CON & 4.21 & 5.33 & 5.37 & 4.93 & 0.096 & 0.003 & $<0.001$ & 0.158 \\
\hline & VVI & 4.05 & 5.23 & 5.12 & 4.64 & & & & \\
\hline & QUE & 4.48 & 6.56 & 5.76 & 4.65 & & & & \\
\hline
\end{tabular}

SEM, standard error of the mean.

1) CON, control diet; $\mathrm{VVI}$, diet with lingonberry leaves addition; QUE, diet with oak bark addition.

${ }^{2)} \mathrm{D}$, main effect of dietary treatment; $T$, main effect of time; $D \times T$, dietary treatment and time interaction effect.

${ }^{3)}$ Gases concentrations were calculated according to Wolin [17]. 
diet seems to have more stabilizing impact on the protozoa population. Such various effects of plant additives may probably be the result of different polyphenolic compounds content present in animal diets. It was shown that VVI diet contained up to twice higher concentration of catechins (condensed tannins) than the QUE diet. Smeriglio et al [18] reported that, the predominant components of oak bark (Quercus robur L.) are hydrolysable tannins, while the contribution of proanthocyanidins (condensed tannins) is rather low, as shown in the present study. Thus, different types of tannins may be probably a significant factor affecting protozoa population. However, we cannot exclude the effect of other biologically active compounds found in such additives on protozoa number. For example, comparing the concentration of various compounds present in lingonberry leaves, up to $12 \%$ content is reported for tannins, while approximately $5 \%$ to $7 \%$ constitutes for arbutin and methylarbutin (phenolic glycosides) [3]. In sheep supplemented with VVI diet an increased number of Ophryoscolex spp. was noted. Such protozoa are mainly involved in the digestion of structural carbohydrates, including cellulose, hemicellulose, and pectin, while simple sugars are used only in small amounts [19]. Conversely, in sheep receiving QUE diet, an increased total number of protozoa, as well as Entodinium spp., Isotricha spp. and Dasytricha ssp., which utilise easily digestible carbohydrates, including starch [19], was observed. Interestingly, an increased number of protozoa may be considered to be an indicator of ruminants' health [20]. In particular, the presence of protozoa has a buffering effect on rumen conditions by engulfing starch granules and slowing down its fermentation, which protects the animal from rapid fluctuations of ruminal $\mathrm{pH}$ and may prevent acidosis [19]. This is of great importance for the animal because microorganisms habituating rumen are sensitive to the $\mathrm{pH}$ changes. Rapid increase or decrease of $\mathrm{pH}$ value can lead to growth and development of specific groups of microorganisms at the expense of others, and thus may significantly alter or even disrupt the digestion of nutrients as well as fermentation pattern. Importantly, the ability of protozoa to detoxify toxins taken up by the host organism from the feed is also known [19].

Interestingly, only QUE diet decreased bacterial mass in the rumen fluid. Looking at the rumen microorganisms and their interdependencies as a whole, the smaller amount of bacteria may be derived from a higher number of protozoa, which engulf bacterial cells and, thus, can modify the size of their population [19]. Bacterial cells are rich source of nitrogenous compounds, which are necessary for protozoan growth and development. Interestingly, comparative studies on faunated and defaunated (ciliate-free) sheep receiving the same diet, showed that predatory activity of protozoa reduced bacterial population by up to $50 \%$ to $90 \%$ primarily in faunated animals [19]. At this moment, it is difficult to propose other more accurate mechanisms of tannins action on an increased number of protozoa. The results of the studies exploring effect of tannins on bacterial population seem to be more explicit than for protozoa. It was shown that bacteria have developed some adaptive mechanisms to tannins, for instance the presence of tannase, enzyme responsible for the hydrolysis of the ester binding of tannic acid between gallic acid and glucose [21]. As shown in the study of Patra et al [21], hydrolysable tannins can be degraded by microorganisms into gallic acid, pyrogallol and phloroglucinol, and then to SCFA. Therefore, it could be possible that some rumen microorganisms have adapted to the presence of hydrolysable tannins in the QUE additive. We also think that QUE diet may create more favorable conditions for the development of some protozoa in the rumen. In fact, it could be possible that bacteria constituted the first line of defense and resist the toxic effect of tannins, indirectly affecting protozoa number. Importantly, it is not excluded that protozoa may also have some mechanisms of adapting to tannins, similar to bacteria. Our suspicions seem to remain only in the sphere of deliberation so far. Thus, this issue still requires more detailed studies both in vivo and in vitro. Unfortunately, in the present study, only bacterial mass was determined. Further subsequent microbiological studies using modern molecular techniques, like real-time polymerase chain reaction (real-time PCR) or polymerase chain reaction-denaturing gradient gel electrophoresis (PCRDGGE), seem to be necessary to explore the effect of tested plant sources on different bacteria species and finally to know if the impact of tannins on bacteria is equal or rather species dependent.

Generally, in the literature, most studies explore the effect of plants containing primarily condensed tannins on rumen microorganisms and the great majority of them were conducted under in vitro conditions. Thus, the results of these researches are often controversial and seem to depend both on the different origin of such compounds and their destination. Thereby, it is of great importance to determine whether tannin-rich plants are: i) used as additives; ii) partially incorporated to the diet, replacing other components; or whether iii) they are offered to the animals as their sole feed. Most studies documented anti-protozoic [22-24] and anti-bacterial $[22,25]$ actions of various tannin-rich plants addition. Furthermore, Aghamohamadi et al [26] reported decreased numbers of Entodinium spp. and Ophryoscolex spp. protozoa, as well as cellulolytic bacteria, after supplementing sheep diet with oak acorn (Quercus perlica). Interestingly, Carulla et al [27] noted that Isotrichidae protozoa seem to be more sensitive to the action of condensed tannins from Acacia mearnsii extract in comparison to Entodinium spp. This effect was not observed in the present study. Similarly, to our observations, Chiquette et al [28] showed increased protozoa number in 
rumen of sheep after Lotus corniculatus and Hedysarum coronarium (condensed tannins) supplementation. Furthermore, in sheep grazing sulla (Hedysarum coronarium) the protozoal number was also increased [29]. Interestingly, the addition of herbal preparation Ruchamax (consisting of 26 different plant extracts) to heifers' diet, significantly increased total protozoa and Entodinium spp. numbers [20] as documented in the current study. On the other hand, there are several studies, which did not show any effect of tannin-rich plants addition on the protozoa population [28,29]. According to above mentioned studies, noteworthy is fact that origin of tannins, can be just as crucial as their types in affecting the number of rumen microfauna.

\section{Indicators of rumen fermentation}

In the present study, the $\mathrm{pH}$ of rumen fluid was within normal range and none of the additions affected its value. The obtained results agree with Śliwiński et al [30], who did not show any differences in $\mathrm{pH}$ after feeding lambs with extract from Castanea sativa (hydrolysable tannins).

Rumen protozoa play an important role in carbohydrate metabolism, but depending on the species composition different fermentation patterns can be observed [19]. Generally, protozoa are believed to be one of the major producers of butyric acid in the rumen [19]. Michałowski [31] indicated that during ruminal carbohydrate fermentation, protozoa and bacteria produced total SCFA with similar intensity, but the main differences were observed in the concentrations of butyric and propionic acids. The formation of acetate was similar in both groups and accounted for over $50 \%$ of total SCFA [31]. Comparing molar concentrations of particular SCFA produced by different groups of microorganisms, Michałowski [31] stated that rumen microfauna were responsible for two-fold greater production of butyrate in the rumen of sheep than bacteria ( $41.3 \%$ vs $20.4 \%$ on average, respectively). Bacteria, in turn, produced higher concentrations of propionate to protozoa ( $22.1 \%$ vs $6.7 \%$ on average, respectively) [31]. Therefore, the composition of microorganisms in the rumen may significantly affect the carbohydrate fermentation pattern. Considering the above facts, it seems that higher molar proportion of butyrate in QUE sheep may primarily result from an increase in total protozoa number. Similar dependencies were also observed in the study of Terrill et al [29] in sheep grazing sulla. Additionally, it cannot be excluded that part of the butyrate in rumen fluid may originate from the microbial degradation of hydrolysable tannins [21]. In turn, elevated concentrations of branchedchain fatty acids (BCFA) in QUE diet may indicate impact of tannins on the rate of dietary protein degradation as well as deamination process. Indeed, rumen bacteria require BCFA to synthesize the carbon skeleton of branched-chain amino acids and long-chain fatty acids [32].
In the literature, the various effects of plant additives on carbohydrate fermentation, which certainly depend on plant materials, their dosage added to ruminants' diet, as well as the presence of various biologically active compounds are documented. On the one hand, several in vitro and in vivo studies showed that the addition of tanniniferous plant materials did not significantly influence SCFA concentrations in rumen [26,33]. On the other hand, some researches have demonstrated some changes regarding total SCFA concentrations as well as their individual types. The study of Chanthakhoun et al [34] showed that feeding swamp buffalo with legume (Phaseolus calcaratus) hay significantly increased SCFA concentration, as well as acetic and propionic acids in rumen. Contrary to the present study, Cieślak et al $[23,24]$ observed an increased concentration of propionic acid and lower acetic to propionic ratio, after using extract from lingonberry or oak bark, which may suggest negative impact of tannins on fiber digestion and cellulolytic microorganisms activity. In the current study, dry plant materials (not extracts) were used. Thus, despite the use of similar plant additives, the final amount of biologically active compounds was lower in a raw product than after extraction, which may partially explain observed differences [3]. By contrast, sheep receiving extract from Acacia mearnsii (condensed tannins) had higher concentrations of butyric and valeric acids in rumen [27]. Similar dependencies were also documented in studies on cows fed with plants containing condensed tannins [35], which were partially confirmed by the results obtained for QUE sheep. In study of Doce et al [36], an increased concentrations of butyric acid in rumen fluid of steers fed diet with different doses of oak leaves (Quercus pyrenaica, hydrolysable tannins) were also documented, which is in agreement with present study.

According to the literature, the production of methane in ruminants mainly depends on diet and composition of microorganisms habituating rumen. Protozoa are important producers of molecular hydrogen in rumen [37], which, in turn, is utilized by methanogens to methane production. Interestingly, methanogen communities can be associated with protozoa or may live in proximity to the protozoan cells [38]. Thus, every single disruption in the protozoa-methanogens relation, may affect the scale of methane production. Hegarty [39], summarizing the results of both in vivo and in vitro studies, showed significant reduction or even complete elimination of the protozoan population in the rumen by diet with high proportion of concentrate, which resulted in a diminution of methane production by approximately $13 \%$. According to the authors, such changes arise because of reduced digestibility of DM, smaller population of methanogens (lower availability of hydrogen) and changes in the proportion of SCFA. Importantly, the inhibition of methanogenesis process by partial or complete elimination (defaunation) of 
the protozoa population (as hydrogen donors) in the rumen have been demonstrated by several authors [37,40-42]. Recently, studies focusing on the mechanism of methanogenesis reduction by dietary treatments, appear with increasing frequency. Cieślak et al $[23,24]$ and Hess et al [43], reported lower methane production after supplementing animal feed with extracts originating from different plants (lingonberry, oak bark and Acacia mearnsii respectively). As reported by authors, the inhibition of methanogenesis was probably caused by the lower number of protozoa and simultaneously increased concentration of propionic acid (methane antagonist) $[23,24]$ by limited ruminal fiber digestion [36].

Unfortunately, despite reported changes in the microorganism population in sheep fed diets with VVI and QUE, the amount of the additives used in the present study seems to be not effective in lowering methane and carbon dioxide concentrations in the rumen. Similar observations were reported in the Krueger et al [35] study, where the addition of mimosa (condensed tannins) or chestnut (hydrolysable tannins) extracts to cow feed rations did not have any significant effect on rumen methane production. It is worth noting that in the present study gas production was estimated according to the stoichiometric calculations of SCFA production, due to the mutual relationships between product and substrate of fermentation reaction [17]. It is a simple way to measure methane and carbon dioxide where it is not physically possible to detect the gases released from the animal, for example in respiration chambers. The accuracy of methane prediction from SCFA concentrations was raised by Wolin [17], who documented that values obtained from the theoretical predictions agree with experimental values. Similarly, the study of Whitelaw et al [44] on steers showed that stoichiometric calculations of methane production from the proportions of SCFA were of the same order of magnitude as results obtained in the respiration chambers. Interestingly, the values obtained from theoretical predictions overestimated methane production by 1.08 on average.

\section{CONCLUSION}

In the present study, small doses of VVI or QUE addition to sheep diets differently affected rumen microorganisms and fermentation parameters. Additionally, QUE diet seems to create more favorable conditions for growth and development of ciliates, which resulted in higher number of total protozoa and Entodinium genus and increased butyrate molar proportion in rumen. The obtained differences can probably reflect various amounts of catechins (condensed tannins) present in plant materials. However, the effect of other heterogeneous compounds found in such plant additives cannot be excluded. Thus, further study on pure extract should be undertaken, but it must be considered that the price of such additives will substantially increase the cost of feed.

Nevertheless, the possibility of using native herbaceous resources in ruminants' diet, is a step forward for the development of sustainable agriculture and is becoming more widespread in recent years.

\section{CONFLICT OF INTEREST}

We certify that there is no conflict of interest with any financial organization regarding the material discussed in the manuscript.

\section{FUNDING}

The study was financed by the Ministry of Science and Higher Education in Poland, grant no. N N311 110138 entitled 'The effect of tannins and oils addition to sheep diets on microorganism population, rumen fermentation, enzymatic activity of pancreatic-biliary juice and lamb quality?

\section{ACKNOWLEDGEMENTS}

We would like to greatly thank the professor Marian Czauderna from the Kielanowski Institute of Animal Physiology and Nutrition Polish Academy of Sciences in Jabłonna (Poland) for his help in calculating gas production.

This work is dedicated to late professor Janusz J. Pająk, our dear friend, a wonderful scientist and, above all, a man with a great heart.

\section{REFERENCES}

1. Russell JB, Rychlik JL. Factors that alter rumen microbial ecology. Science 2001;292:1119-22. https://doi.org/10.1126/ science. 1058830

2. Li M, Penner GB, Hernandez-Sanabria E, Oba M, Guan LL. Effects of sampling location and time, and host animal on assessment of bacterial diversity and fermentation parameters in the bovine rumen. J Appl Microbiol 2009;107:1924-34. https://doi.org/10.1111/j.1365-2672.2009.04376.x

3. Duda-Chodak A, Tarko T, Rus M. Antioxidant activity and total polyphenol content of selected herbal medicinal products used in Poland. Herb Pol 2011;57:48-61.

4. Elansary HO, Szopa A, Kubica P, et al. Polyphenol profile and pharmaceutical potential of Quercus spp. bark extracts. Plants 2019;8:486. https://doi.org/10.3390/plants8110486

5. Mueller-Harvey I. Analysis of hydrolysable tannins. Anim Feed Sci Technol 2001;91:3-20. https://doi.org/10.1016/S03778401(01)00227-9

6. Kylli P, Nohynek L, Puupponen-Pimiä R, et al. Lingonberry 
(Vaccinium vitis-idaea) and European cranberry (Vaccinium microcarpon) proanthocyanidins: isolation, identification, and bioactivities. J Agric Food Chem 2011;59:3373-84. https://doi.org/10.1021/jf104621e

7. McSweeney CS, Palmer B, McNeill DM, Krause DO. Microbial interactions with tannins: nutritional consequences for ruminants. Anim Feed Sci Technol 2001;91:83-93. https:// doi.org/10.1016/S0377-8401(01)00232-2

8. Patra AK, Saxena J. Dietary phytochemicals as rumen modifiers: a review of the effects on microbial populations. Antonie Van Leeuwenhoek 2009;96:363-75. https://doi.org/10.1007/ s10482-009-9364-1

9. Majewska MP, Pająk JJ, Skomiał J, Miltko R, Kowalik B. The effect of lingonberry leaves and oak cortex addition to sheep diets on pancreatic enzymes activity. J Anim Feed Sci 2017; 26:354-8. https://doi.org/10.22358/jafs/79748/2017

10. Kuhla S, Ebmeier C. Investigations of the tannin content of horse beans. 1. Methodical investigations for the purpose of determining condensed tannins in horse beans. Arch Tierernahr 1981;31:573-88.

11.IZ PIB-INRA. Nutrition standards for ruminants. The value of French and national feeding stuffs for ruminants. Kraków, Poland: IZ PIB-INRA; 2009.

12. AOAC International. Official methods of analysis of AOAC International.18th ed. Arlington, VA, USA: AOAC International; 2011.

13. Dogiel VA. Monographie der familie ophryoscolecidae. Ried im Innkreis, Austria: Fischer; 1927.

14.Miltko R, Pietrzak M, Bełżecki G, Wereszka K, Michałowski T, Hackstein JHP. Isolation and in vitro cultivation of the fibrolytic rumen ciliate Eremoplastron (Eudiplodinium) dilobum. Eur J Protistol 2015;51:109-17. https://doi.org/10.1016/j.ejop. 2014.11.002

15. Michałowski T, Bełżecki G, Kwiatkowska E, Pająk JJ. The effect of selected rumen fauna on fibrolytic enzyme activities, bacterial mass, fibre disappearance and fermentation pattern in sheep. J Anim Feed Sci 2003;12:45-64. https://doi.org/10. 22358/jafs/67642/2003

16. Miltko R, Rozbicka-Wieczorek JA, Więsyk E, Czauderna M. The influence of different chemical forms of selenium added to the diet including carnosic acid, fish oil and rapeseed oil on the formation of volatile fatty acids and methane in the rumen, and fatty acid profiles in the rumen content and muscles of lambs. Acta Vet 2016;66:373-91. https://doi.org/10. 1515/acve-2016-0032

17. Wolin MJ. The rumen fermentation: a model for microbial interactions in anaerobic ecosystems. In: Alexander M, editor. Advances microbial ecology. Boston, MA, USA: Springer; 1979. pp. 49-77. https://doi.org/10.1007/978-1-4615-8279-3_2

18. Smeriglio A, Barreca D, Bellocco E, Trombetta D. Proanthocyanidins and hydrolysable tannins: occurrence, dietary intake and pharmacological effects. Br J Pharmacol 2017;174:
1244-62. https://doi.org/10.1111/bph.13630

19. Williams AG, Coleman GS. The rumen protozoa. In: Hobson PN, Stewart CS, editors. The rumen microbial ecosystem. 2nd ed. Berlin, Germany: Springer Science \& Business Media; 1997.

20.Kowalik B, Majewska MP, Pająk JJ, Skomiał J. Effect of the preparation Ruchamax in diets for heifers on the population of ciliates, rumen fermentation, and biochemical parameters of blood. Med Weter 2015;71:578-82.

21.Patra AK, Min BR, Saxena J. Dietary tannins on microbial ecology of the gastrointestinal tract in ruminants. In: Patra AK, editor. Dietary phytochemicals and microbes. Dordrecht, Netherlands: Springer; 2012.

22. Abarghuei MJ, Rouzbehan Y, Alipour D. Effect of oak (Quercus libani Oliv.) leave tannin on ruminal fermentation of sheep. J Agric Sci Technol 2011;13:1021-32.

23.Cieślak A, Zmora P, Pers-Kamczyc E, Szumacher-Strabel M. Effects of tannins source (Vaccinium vitis idaea L.) on rumen microbial fermentation in vivo. Anim Feed Sci Technol 2012; 176:102-6. https://doi.org/10.1016/j.anifeedsci.2012.07.012

24.Cieślak A, Zmora P, Pers-Kamczyc E, et al. Effects of two sources of tannins (Quercus L. and Vaccinium vitis idaea L.) on rumen microbial fermentation: an in vitro study. Ital J Anim Sci 2014;13:3133. https://doi.org/10.4081/ijas.2014. 3133

25.Min BR, Attwood GT, Reilly K, et al. Lotus corniculatus condensed tannins decrease in vivo populations of proteolytic bacteria and affect nitrogen metabolism in the rumen of sheep. Can J Microbiol 2002;48:911-21. https://doi.org/10. 1139/w02-087

26. Aghamohamadi N, Hozhabri F, Alipour D. Effect of oak acorn (Quercus persica) on ruminal fermentation of sheep. Small Rumin Res 2014;120:42-50. https://doi.org/10.1016/j.small rumres.2014.04.015

27. Carulla JE, Kreuzer M, Machmüller A, Hess HD. Supplementation of Acacia mearnsii tannins decreases methanogenesis and urinary nitrogen in forage-fed sheep. Aust J Agric Res 2005;56:961-70. https://doi.org/10.1071/AR05022

28. Chiquette J, Cheng KJ, Rode LM, Milligan LP. Effect of tannin content in two isosynthetic strains of birdsfoot trefoil (Lotus corniculatus L.) on feed digestibility and rumen fluid composition in sheep. Can J Anim Sci 1989;69:1031-9. https://doi. org/10.4141/cjas89-117

29. Terrill TH, Douglas GB, Foote AG, Purchas RW, Wilson GF, Barry TN. Effect of condensed tannins upon body growth, wool growth and rumen metabolism in sheep grazing sulla (Hedysarum coronarium) and perennial pasture. J Agric Sci 1992;119:265-73. https://doi.org/10.1017/S00218596000 14192

30.Śliwiński BJ, Kreuzer M, Wettstein HR, Machmüller A. Rumen fermentation and nitrogen balance of lambs fed diets containing plant extracts rich in tannins and saponins, and asso- 
ciated emissions of nitrogen and methane. Arch Anim Nutr 2002;56:379-92. https://doi.org/10.1080/00039420215633

31. Michałowski T. The volatile fatty acids production by ciliate protozoa in the rumen of sheep. Acta Protozool 1987;26: 335-45.

32. Yang CMJ. Response of forage fiber degradation by ruminal microorganisms to branched-chain volatile fatty acids, amino acids, and dipeptides. J Dairy Sci 2002;85:1183-90. https:// doi.org/10.3168/jds.S0022-0302(02)74181-7

33. Szczechowiak J, Szumacher-Strabel M, El-Sherbiny M, PersKamczyc E, Pawlak P, Cieślak A. Rumen fermentation, methane concentration and fatty acid proportion in the rumen and milk of dairy cows fed condensed tannin and/or fish-soybean oils blend. Anim Feed Sci Technol 2016;216: 93-107. https://doi.org/10.1016/j.anifeedsci.2016.03.014

34. Chanthakhoun V, Wanapat M, Wachirapakorn C, Wanapat S. Effect of legume (Phaseolus calcaratus) hay supplementation on rumen microorganisms, fermentation and nutrient digestibility in swamp buffalo. Livest Sci 2011;140:17-23. https://doi.org/10.1016/j.livsci.2011.02.003

35. Krueger WK, Gutierrez-Bañuelos H, Carstens GE, et al. Effects of dietary tannin source on performance, feed efficiency, ruminal fermentation, and carcass and non-carcass traits in steers fed a high-grain diet. Anim Feed Sci Technol 2010;159:1-9. https://doi.org/10.1016/j.anifeedsci.2010.05. 003

36. Doce RR, Hervás G, Belenguer A, Toral PG, Giráldez FJ, Frutos P. Effect of the administration of young oak (Quercus pyrenaica) leaves to cattle on ruminal fermentation. Anim Feed Sci Technol 2009;150:75-85. https://doi.org/10.1016/j.anifeedsci. 2008.08.005
37.Morgavi DP, Forano E, Martin C, Newbold CJ. Microbial ecosystem and methanogenesis in ruminants. Animal 2010; 4:1024-36. https://doi.org/10.1017/S1751731110000546

38. Newbold CJ, de la Fuente G, Belanche A, Ramos-Morales E, McEwan NR. The role of ciliate protozoa in the rumen. Front Microbiol 2015;6:1313. https://doi.org/10.3389/fmicb.2015. 01313

39. Hegarty RS. Reducing rumen methane emissions through elimination of rumen protozoa. Aust J Agric Res 1999;50: 1321-8. https://doi.org/10.1071/AR99008

40.Cieślak A, Szumacher-Strabel M, Stochmal A, Oleszek W. Plant components with specific activities against rumen methanogens. Animal 2013;7(Suppl 2):253-65. https://doi. org/10.1017/S1751731113000852

41. Haque MN. Dietary manipulation: a sustainable way to mitigate methane emissions from ruminants. J Anim Sci Technol 2018;60:15. https://doi.org/10.1186/s40781-018-0175-7

42.Salami SA, Valenti B, Bella M, et al. Characterisation of the ruminal fermentation and microbiome in lambs supplemented with hydrolysable and condensed tannins. FEMS Microbiol Ecol 2018;94:fiy061. https://doi.org/10.1093/femsec/ fiy061

43. Hess HD, Tiemann TT, Noto F, Carulla JE, Kreuzer M. Strategic use of tannins as means to limit methane emission from ruminant livestock. Int Congr Ser 2006;1293:164-7. https:// doi.org/10.1016/j.ics.2006.01.010

44. Whitelaw FG, Eadie JM, Bruce LA, Shand WJ. Methane formation in faunated and ciliate-free cattle and its relationship with rumen volatile fatty acid proportions. Br J Nutr 1984; 52:261-75. https://doi.org/10.1079/BJN19840094 